\title{
Competições de conhecimentos universitários: Método inovador de incentivo à aprendizagem
}

\author{
Rivalina Maria Macêdo Fernandes ${ }^{1}$; Martha Maria Macedo Bezerra ${ }^{2}$; \\ Julyanne de Oliveira Paes Barreto ${ }^{3}$; Athena de Albuquerque Farias ${ }^{4}$
}

\begin{abstract}
Resumo: As competições universitárias tem tomado cada vez mais espaço, principalmente por ser uma forma de descobrir talentos, encontrar soluções para problemas, premiar os vencedores por suas capacidades, e, principalmente, por ter se revelado como método eficaz no estímulo a aprendizagem estudantil, visto que desperta no estudante o desejo de se auto desafiar para fins de apresentar suas melhores habilidades. Este estudo discute as competições de conhecimentos universitários como metodologia ativa de incentivo a aprendizagem. Os resultados levam a crer que as competições acadêmicas são um método exitoso de incentivo a aprendizagem, configurandose como algo favorável e complementar à formação estudantil. Mesmo assim ainda carece de critérios para uma formalização para que sejam incorporadas aos currículos, embora sejam reconhecidas como incentivo ao ensino e aprendizagem e, a aprimoração das capacidades e habilidades dos universitários.
\end{abstract}

Palavras-chave: Aprendizagem universitária, Metodologias ativas, Competições.

\section{University Knowledge Competitions: An Innovative Method of Encouraging Learning}

\begin{abstract}
University competitions have taken more and more space, mainly because it is a way of discovering talent, finding solutions to problems, rewarding the winners for their abilities, and above all for proving to be an effective method in stimulating student learning, since it arouses in the student the desire to self-challenge for the purpose of presenting his best abilities. This study discusses the competitions of university knowledge as an active methodology to encourage learning. The results lead us to believe that academic competitions are a successful method of stimulating learning, being configured as something favorable and complementary to student training. Even so, it still lacks criteria for a formalization to be incorporated into the curricula, although they are recognized as an incentive for teaching and learning and for the improvement of the abilities and abilities of university students.
\end{abstract}

Keywords: University apprenticeship, Active methodologies, Competitions.

\footnotetext{
${ }^{1}$ Mestrado em Gestão em Organizações Aprendentes pela Universidade Federal da Paraíba, Brasil. psicóloga do Centro Universitário UNINTA, Brasil. Contato: rivalinafernandes@gmail.com;

${ }^{2}$ Mestrado em Educação pela Universidade Estadual do Ceará. Possui Licenciatura em Pedagogia pela Universidade Regional do Cariri, especialização em Língua Portuguesa pela Universidade Estadual do Ceará, especialização em Políticas Públicas pela Universidade Regional do Cariri, especialisação em Saude Mental e Psiquiatria pela Universidade Estadual do Vale do Acaraú. Atualmente, cursa o Doutorado em Saúde Coletiva pela Faculdade de Medicina do ABC. Professora concursada da Secretaria de Educação do Estado do Ceará. Professora da Rede Municipal de Juazeiro do Norte. Contato: marthamacedo2016@gmail.com;

${ }^{3}$ Advogada formada pela faculdade Metropolitana - Jaboatão dos Guararapes - Pernambubo. Especialização em Gestão de Pessoas pelo Faculdades Integradas de Cruzeiro, Brasil. Contato: July_paes2@ @otmail.com;

${ }^{4}$ Advogada formada pelo Centro Universitário dos Guararapes - UNIFG. Máster in Law Sustainable Development.

Università degli Studi di Milano - IT. Especialista em Direito Processual do Trabalho pela Faculdades Integradas de Cruzeiro - SP. Editora Adjunta do Periódico Científico Amadeus International Multidisciplinary Journal. Contato: athena.farias@gmail.com.
} 


\section{Introdução}

Desde meados de 1990, o ensino superior tem se expandido de forma acelerada, o que veio acompanhado de diversos desafios quanto ao ensino e a aprendizagem, para fins de se manter a qualidade e profundidade da educação. Somado a isso, os métodos tradicionais de ensino passaram a apresentar limitações, pois a mera memorização de conteúdos passou a ser insuficiente em um mundo que demanda, cada vez mais, de conhecimentos dinâmicos e inovadores, bem como de profissionais com iniciativa e capacidade de compreender e solucionar problemas. iniciativas e comportamento na compreensão e resolução de problemas (HARRISON e JEPSEN, 2015).

Nesse contexto, os concursos universitários de conhecimentos têm sido classificados como metodologia ativa de aprendizagem, sendo indicados e utilizadas como alternativa inovadora e complementar à formação acadêmica dos alunos. Isto ocorre porque em oposição a metodologia tradicionalista, consiste em forma de educação problematizante, em que, por meio da apresentação de um problema a ser solucionado, os estudantes ocupam o papel de protagonistas da educação, refletem e agem com autonomia, aplicando seu aprendizado de vida, profissional e, sobretudo, acadêmico.

As competições universitárias tem tomado cada vez mais espaço, principalmente por ser uma forma de descobrir talentos, encontrar soluções para problemas, premiar os vencedores por suas capacidades, e, principalmente, por ter se revelado como método eficaz no estímulo a aprendizagem estudantil, visto que desperta no estudante o desejo de se auto desafiar para fins de apresentar suas melhores habilidades.

Sem dúvidas, a busca por opções complementares ao ensino e com base em um processo de ensino ativo-problematizador, é algo difícil e restrito, mas que é visto pelos professores como algo que acresce ao aprendizado dos estudantes. Com base nisso, o presente estudo visa discutir o uso dos prêmios e concursos universitários, demonstrando que esse se assemelha a uma forma de metodologias ativas de ensino, que tem se revelado útil e eficaz no estimulo a aprendizagem estudantil e desenvolvimento das capacidades dos acadêmicos. 


\section{Concursos e competições universitárias: uma nova forma de incentivo à aprendizagem?}

As competições acadêmicas universitárias, tem o objetivo principal de testar as habilidades dos estudantes para além das provas e debates em sala. Além disso, trata-se de método útil e eficaz de visibilidade profissional e de obtenção de oportunidades. Como forma de incentivo a participação, os concursos oferecem dinheiro, bolsas de estudo, congressos e viagens, como forma de premiação aos vencedores.

É bem verdade que a prática científica não deve se basear na mera competição entre pesquisadores, pois isso poderia deturpar a natureza de pesquisa inerente da prática da academia. No entanto, quando inserido em um certo contexto e devidamente pautado em regras previamente estabelecidas, a competição pode ser algo saudável no campo acadêmico, devido ao seu potencial para inspirar a busca pelo desenvolvimento de soluções em potencial para problemas relevantes, das quais podem decorrer grandes avanços na comunidade científica.

Sendo assim, apesar de haver uma premiação dar uma falta impressão de competição entre os alunos, eles, na verdade, estão disputando com eles mesmos. Na verdade, esse tipo de competição consigo mesmo ocorre em toda e qualquer atividade acadêmica, pois o pesquisador precisa superar o que ele já tem de melhor para poder obter melhores resultados. Logo, um concurso acadêmico é, primordialmente, um desafio com fulcro de testar as técnicas e capacidades cognitivas do pesquisador.

Essas competições acadêmicas também servem de inspiração para os futuros cientistas, para que estes pensem além dos livros, desenvolvendo, inclusive seu campo de visão e pensamentos. Ademais, as adversidades que podem ocorrer durante uma competição, é capaz de estimular o trabalho em equipe, bem como a desenvolver as habilidades dos estudantes para enfrentar e dirimir problemas.

Tendo em vista as vantagens de uma competição acadêmica, jovens pesquisadores são constantemente estimulados a participar dessas atividades, desenvolvendo trabalhos robustos. Inclusive, investir em competições acadêmicas pode dar ensejo ao início de projetos ambiciosos, grande prestígio acadêmico e até retorno financeiro, principalmente se o prêmio for um financiamento de pesquisas a ser realizada pelo cientista ou algum projeto de colaboração.

Os concursos acadêmicos é utilizado há longas datas e envolvem as mais diversas áreas de conhecimento, como pode se verificar no Prêmio Espanhol de Longitude de 1567, no Prêmio de Conservação de Alimentos realizado por Napoleão em 1795, o Prêmio das Estradas de Ferro 
e Locomotivas de Liverpool e Manchester de 1829; o Prêmio da Fundação Rockefeller para Rápido STD de 1994 e no Desafio Lunar Google realizado em 2007. Ou seja, além de existirem há muito tempo e envolverem os mais variados campos de conhecimentos, também são utilizados em nível global (FREY, 2006; FREY; NECKERMANN, 2008; BALLANTYNE, 2014).

No Brasil esse método de incentivo ao estudo e aprendizagem ainda é recente, porém crescente no país, com uso de diversos tipos de organizações e área de conhecimento, como ciência, publicidade, arte, comida, literatura e cinema, e premiação principalmente com condecorações, certificados, honrarias, dentre outros (HARRISON; JEPSEN, 2015, p. 1). Cabe comentar que, muitas vezes, os prêmios não-monetários são considerados desperdício de tempo (FREY; GALLUS, 2014), o que não devia ocorrer, pois, conforme comentado, as competições acadêmicas são momento de se fazer networking, bem como do estudante apresentar sua dinâmica e conhecimentos para o mundo, seja dos negócios, seja acadêmico.

Nesse cenário, conforme dados levantados por Edson Sadao lizuka (2016) os concursos acadêmicos e de prêmios universitários, possuem termo inicial datado de meados de 1980 e até o ano 2000. Em razão do sucesso desse método de aprendizagem, em 2016 mais vinte e três competições, revelando uma tendência de crescimento nesse sentido:

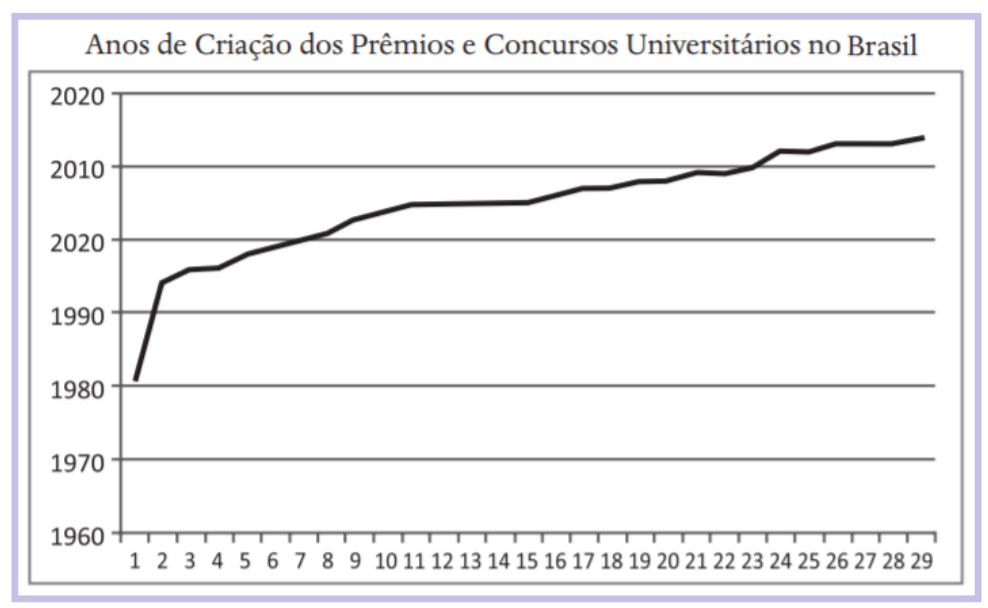

Fonte: Iizuka (2016, p. 95).

Essas competições costumam girar em torno de problemas cuja solução envolve a criação de novos produtos ou serviços, compilação de informações e dados sobre algo ou identificação de práticas inovadoras. Para isso, via de regra, esses concursos premiam indivíduos ou organizações que apresentem uma solução adequada para certo desafio posto 
(BASTOS; KUULUVAINEN; BRAGA, 2015, p. 5), da seguinte forma: uma instituição identifica um problema que precisa de solução, divulga a necessidade de resolução e oferece alguma recompensa, seja monetária ou de mérito, para aquele que desenvolver a melhor solução. Ademais, também são utilizados com o objetivo de encontrar talentos emergentes, bem como de colaborar com a inserção desses jovens no mercado de trabalho. Nesse cenário, o oferecimento de um prêmio, seja simbólico ou material, aos vencedores do desafio, é algo que acaba por atrair o interesse de maior quantitativo de pessoas a participarem do evento (BALLANTYNE, 2014, p. 4).

No Brasil, a Revista Exame elaborou, em 2014, uma matéria virtual na qual selecionou as competições mais interessantes, ao redor do mundo, direcionadas para alunos de marketing, administração, arquitetura, direito, entre outras, sendo elas:

(i) Global Marketing Competition, que consiste em jogo virtual que simula a atividade empresarial para que os universitários testam seus conhecimentos empresariais;

(ii) (EDP University Challenge, que estimula os estudantes a criarem projetos com base nos programas socioambientais propostos pela companhia;

(iii) FRESHHH, trata-se de competição online elaborada pelo MOL Group, em que os universitários e pós-graduandos são desafiados a comandar a sua própria companhia de petróleo e gás, Freshhhland, desde a sua criação até a construção de refinarias;

(iv) The Fresh Connection Apics Global Student Challenge, competição que testa os conhecimentos dos estudantes em gerenciamento de supply chain;

(v) Brightest Minds Contest, voltada especificamente para alunos de MBA ou MBA, onde os participantes farão uma simulação por meio da plataforma GMAT Tutor, de autoria da revista Economist;

(vi) Cima Global Business Competition, realizada pelo Chartered Institute of Management Accountants (CIMA) em conjunto com a Barclays, para analisar as habilidades em consultoria de gestão de negócios dos participantes;

(vii) Willem C. Vis Moot, que testa os conhecimentos dos estudantes de direito na área de arbitragem;

(viii) Willem C. Vis East Moot, que também testa os alunos do curso de direito em relação à arbitragem;

(ix) Moot Madrid, em que serão analisados os conhecimentos jurídicos dos alunos das faculdades de direito. 
Em nível nacional, conforme análise realizada por Edson Sadao Izuca (2016, p. 86-93) acerca das dos Prêmios e Concursos Universitários no país, o rol de principais concursos de prêmios é bem mais extenso, dos quais iremos pontuas vinte, são os seguintes:

(i) Transforma Brasil, que versa sobre o tema de negócios sociais, estimulando os universitários a desenvolverem projetos com relevante impacto social e/ ou ambiental;

(ii) Desafio Universitário Empreendedor, que busca desenvolver o empreendedorismo, bem como preparar os estudantes para o mercado de trabalho;

(iii) Prêmio Jovem Cientista, que objetiva revelar novos talentos, impulsionar a pesquisa e investir em jovens pesquisadores que desejem colaborar para a inovação e busca de soluções para desafios postos;

(iv) Prêmio Fecomercio de Sustentabilidade, cujo objetivo é encontrar ideias inovadoras que colaborem na reução de impactos socioeconômicos e ambientais, no país ou no mundo;

(v) Prêmio Santander Empreendedorismo, que visa identificar projetos com postura empreendedora;

(vi) Prêmio Santander Ciência e Inovação, que busca estimular a pesquisa científica de caráter inovador;

(vii) Torneio Gerencial, com o escopo de possibilitar que os participantes exerçam empresa por meio de simulações, para fins de se aprimorarem e se capacitarem;

(viii) Prêmio Odebrecht para o Desenvolvimento Sustentável Reconhecer, que incentiva os universitários a desenvolver projetos e gerar conhecimentos sobre engenharia sustentáveis, por meio da apresentação de novas ideias à comunidade acadêmica e à sociedade;

(ix) Prêmio EDP Inovação Incentivar a inovação, que visa estimular o empreendedorismo sustentável no país Brasil por meio do incentivo ao desenvolvimento de propostas tecnológicas e modelos de negócios;

(x) Competição Fórmula SAE Brasil Combustão, cuja finalidade difundir e intercambiar técnicas e conhecimentos de Engenharia náutica; 
(xi) Competição Fórmula SAE Brasil, que envolve a difusão e o permuta de conhecimentos de Engenharia Automotiva, com foco nos veículos elétricos de Tecnologia Híbrida;

(xii) Competição SAE Brasil Aerodesign, relacionado a difusão e troca conhecimentos de Engenharia Aeronáutica da mobilidade;

(xiii) Competição Baja SAE Brasil-Petrobras, que é um desafio voltado para estudantes de engenharia, que oportuniza que os estudantes apliquem os conhecimentos assimilados em classe, desde o projeto até a execução, com vistas a incrementar sua preparação para o mercado, tornando-o mais competitivo.

(xiv) Maratona De Programação, voltada para os estudantes de computação, busca estimular a criatividade, o trabalho em equipe, a busca por soluções inovadoras de software e desenvolvimento da habilidade de solucionar problemas em situações de pressão. De ano para ano, temos observado que as instituições e principalmente as grandes empresas da área têm valorizado os alunos que participam da Maratona

(xv) Concurso Travessia FEI O Concurso Travessia, que visa desenvolver conhecimentos e habilidades dos universitários, por meio do estímulo do raciocínio, do trabalho em equipe e outros princípios essenciais a formação profissional e indivíduo.

(xvi) Instituto 3M Para Estudantes Universitários, que apoia projetos de extensão voltados à promoção do desenvolvimento social, buscando projetos que foquem em tecnologias sociais voltadas para a educação, saúde e/ou meio ambiente.

(xvii) Prêmio Santander Universidade Solidária, cujo foco encontra-se em projetos voltados para a geração de renda; Batalha de Conceitos Estimular, visa desenvolver criatividade e aumentar a experiência do acadêmico, por meio da aplicação prática do que foi aprendido na universidade;

(xviii) Prêmio Tesouro Nacional, cuja finalidade é estimular o estudo e pesquisa no campo de Finanças Públicas, sendo premiados os trabalhos que além de qualidade técnica, sejam aplicáveis na Administração Pública.

(xix) Prêmio SEAE de Monografias em Defesa da Concorrência e Regulação da Atividade Econômica, essa competição busca estimular a pesquisa no campo da defesa da concorrência e da regulação da atividade econômica, bem como visa difundir esses assuntos na comunidade acadêmica e sociedade como um todo, 
devendo os trabalhos possuírem qualidade técnica e possibilidade de aplicabilidade na Administração Pública.

Ademais, de uma análise dos concursos acadêmicos nacionais, é possível dividi-los em seis categorias: (i) que incentivam o empreendedorismo dos estudantes, tais como ocorre no Santander de Empreendedorismo e o Transformar Brasil; (ii) que visam estimular a competência acadêmica e científica, como pode se observar no Prêmio CNI de Economiae no Prêmio SOF de monografia; (iii) que objetivam reconhecer habilidades dos estudantes no campo da arte e cultura, tal como o Prêmio Saraiva; (iv) que buscam estimular a capacidade para solucionar problemas diversos, como a Maratona de Programação; (v) aqueles que trabalham a visão cidadã dos participantes, assim como o Prêmio Odebrecht de Sustentabilidade e do Instituto 3M para Universitários; e (vi) os que visam desenvolver o aprendizado dos acadêmicos quanto a oratória e comunicação, tal como o Young Persons World Lecture Competition (IIZUKA, 2016, p. 94).

Conforme comentado, esses concursos são iniciativas que aumentam as oportunidades para os estudantes universitários, para que estes, não só coloquem em prática seus conhecimentos e habilidades, mas colabora na busca por soluções de problemas presentes em organizações públicas ou privadas (FREY, 2006; FREY; NECKERMANN, 2008; BALLANTYNE, 2014). Nessa perspectiva, como os concursos estimulam que os estudantes utilizem e superem suas capacidades cognitivas, eles acabam configurando uma forma de processo de aprendizagem:

[...] um resultado muitas vezes esquecido como fruto dos Prêmios é que eles podem funcionar como ambientes de aprendizagem [...] (prêmio) tem potencial para criar um espaço para a experimentação, promovendo soluções mais eficazes, em um espaço colaborativo, no qual atuam diversos participantes, com uma variedade de ideias. (BASTOS; KUULUVAINEN; BRAGA, 2015, p. 6).

O processo de aprendizagem ele pode ser definido pelas seguintes principais etapas: (i) memorização; (ii) anotação, (iii) descrição, (iv) explicação, e (v) prática, onde a prática passiva, no plano na teoria, deve ser complementado pela prática ativa, representada pela prática em si, que irá consolidar e aprimorar o aprendido. Essa consolidação e aprimoração pode ser verificada no gráfico abaixo: 


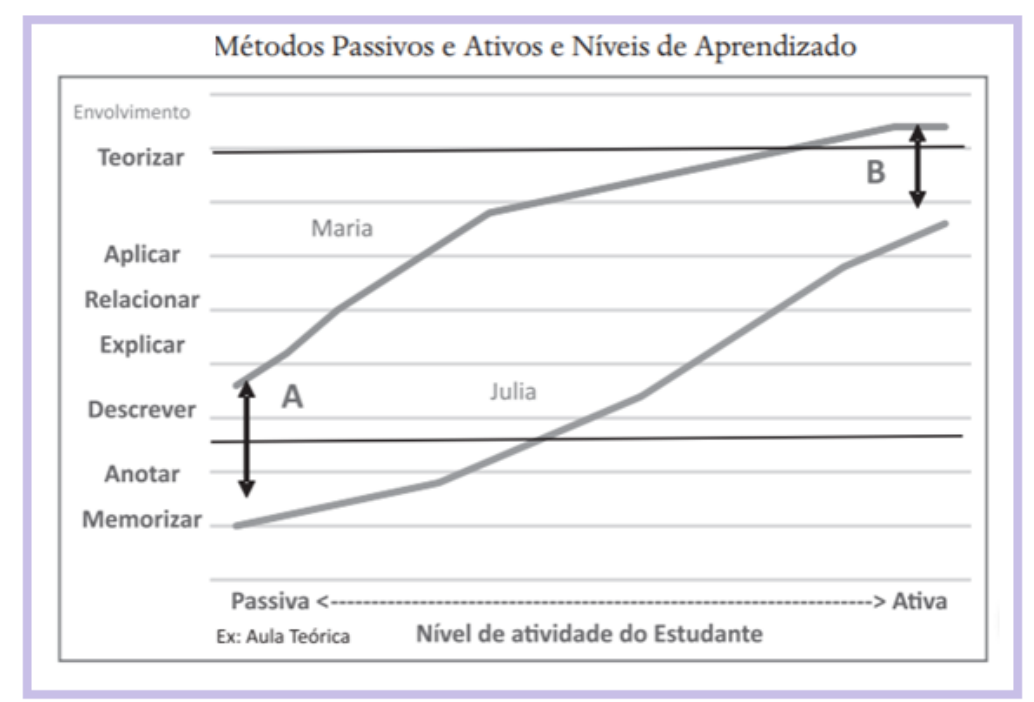

Fonte: Adaptado de Biggs e Tang (2007)

Como os concursos acadêmicos nasceram com o propósito de incentivar e melhorar o processo de aprendizagem, as instituições, desde o momento da organização do evento, buscam planejar suas ações com base nesse propósito (BASTOS; KUULUVAINEN; BRAGA, 2015). Isso foi confirmado por pesquisa realizada pela McKinsey and Company (2009) quanto aos principais prêmios no mundo, que revelou que 35\% das competições objetivaram melhorar as habilidades e conhecimentos dos participantes.

Sendo assim, os concursos acadêmicos possuem potencial aproveitamento no sentido de estímulo e aprimoramento do aprendizado, uma vez que desafia o aluno a superar e trabalhar suas capacidades cognitivas, o que é complementado pela vontade das instituições em colaborar para esse incentivo ao aprendizado, como foi confirmado pela pesquisa da McKinsey and Company , que demonstrou que mais de um terço dos concursos acadêmicos tinham o objetivo principal de auxiliar na aprendizagem estudantil.

\section{Competições acadêmicas: métodos ativos vs. métodos passivos de ensino e aprendizagem}

A metodologia tradicional de ensino é passiva, onde há o professor como figura principal do modelo, e os alunos, como sujeitos passivos, que apenas escutam e devem assimilam as informações apresentadas em sala de aula. No entanto, não é consiste no método mais eficaz de aprendizagem, tendo em vista que se limita ao escutar de informações. 
De fato, o método possui uma vantagem, que consiste em concentrar o poder e controle da sala na figura do professor, que é visto como detentor do conhecimento (PINHO et al., 2010). No entanto, as desvantagens são bem mais caras, pois os alunos apenas escutam e buscam assimilar o que é ensinado, o que não estimula o senso crítico desses (BACKES ET AL, 2010; MEZZARI, 2011; WEINTRAUB; HAWLITSCHEK; JOÃO, 2011), além disso, o professor não sabe se realmente os educandos aprenderam com o conteúdo ministrado em classe (TEÓFILO; DIAS, 2009). Outra desvantagem inerente a metodologia passiva de ensino, está relacionada a dificuldade de desenvolvimento dos alunos, uma vez que esse método não estimula a iniciativa, a criatividade e a autodireção. (HADDAD ET AL,1993, p. 98).

Por sua vez, no método ativo de aprendizagem, largamente utilizado pelos construtivistas, o aluno atua como sujeito ativo no processo de ensino e aprendizagem, sendo o professor um agente facilitador que deve orientar o aluno na buscar e desenvolvimento dos seus conhecimentos. Nessa metodologia de ensino, tanto o professor quanto o aluno, possuem acesso aos meios disponíveis para consulta, tais como livros, internet, revistas, dentre outros. Com isso, o docente não é o único que tem acesso aos conteúdos a serem lecionados, já que os educandos possuem acesso aos mesmos meios de pesquisa (CHAHUÁN-JIMÉNEZ, 2009). Nesse caso, deve-se ressaltar que a desvantagem envolve a dificuldade do professor em conduzir a turma, pois cada educando acaba desenvolvendo um meio próprio de estudo (HADDAD et al., 1993; PINHO et al., 2010).

De qualquer forma, analisando os prós e contras de cada metodologia, os pesquisadores tendem a defender o método de ensino que foque mais no aluno e que busque utilizar de suas experiências e vivências como forma de assimilar o ensinado, devendo o professor ocupar o lugar de auxiliador do processo (ALCADIPANI; BRESLER, 2000; MASSETO, 2007).

Os principais métodos utilizado em cada modelo, são os seguintes:

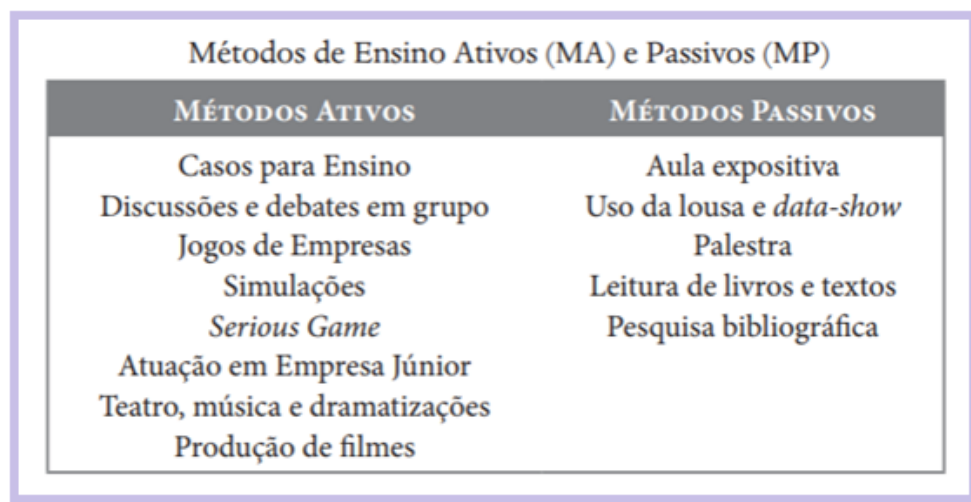

Fonte: Adaptado de Oliveira, Muriba e Casado (2005, p. 7). 
O método de ensino ativo pode ser exemplificado por meio do Ciclo de Kolb, que correlaciona quatro etapas principais demonstrando a correlação e dependência das mesmas em um processo de ensino e aprendizagem ativo, com o objetivo principal de desenvolver a capacidade reflexiva do estudante:

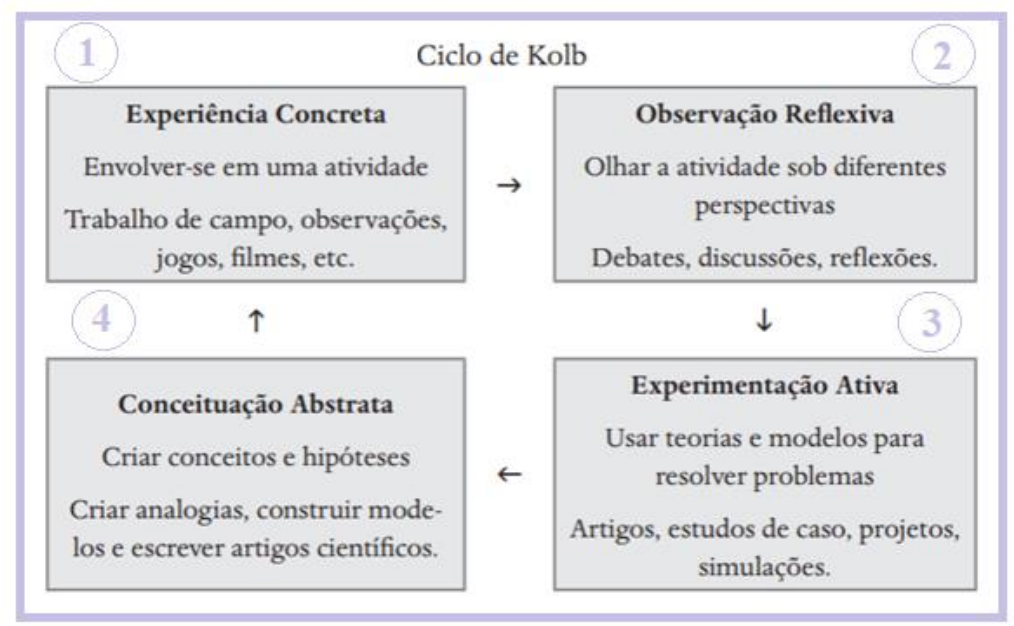

Fonte: Adaptado de Oliveira, Muriba e Casado (2005, p. 4).

Conforme pode se inferir do esquema, o ciclo de Kolb: (i) tem início em uma experiência concreta e, a partir dela, os alunos se envolveram e aprenderão com a atividade; (ii) após, a segunda etapa é carregada de uma observação reflexiva, em que o estudante deve buscar elementos que justifiquem sua compreensão do tema, (iii) na terceira fase, os educandos devem experimentar de forma ativa os modelos e teorias aprendidos, com fulcro de verificar, na prática, a aplicabilidade do aprendido na resolução de problemas; e, por, fim, o estudante mergulha em um processo reflexivo e abstrato, no qual será estimulado a criarem conceitos e hipóteses sobre o tema aprendido. Ao final do ciclo, espera-se que o aluno seja capaz de refletir e amadurecer seus conhecimentos, o que colaborará para a compreensão mais aprofundada da realidade e aplicação em experiências concretas.

De fato, os métodos de ensino ativos são mais eficazes para estimular o protagonismo do estudante no processo de aprendizagem, pois são incentivados a buscar uma forma inovadora para solução dos problemas. Nessa metodologia, os educadores ocuparão a posição de orientadores e os alunos tomarão frente da situação, agindo de forma ativa na buscam do conhecimento, por meio de desafios práticos que lhes são apresentados, o que colabora para o 
desenvolvimento cognitivo do aluno, bem como para o seu senso de adaptação as situações de mudança e adversidades (OLIVEIRA; MURITIBA; CASADO, 2005).

Diante do exposto, conforme pode se inferir dos dados apresentados, as competições universitárias possuem o condão de incrementar o processo de aprendizagem por meio do estimulo expansionista das habilidades técnicas e teóricas adquiridas pelos alunos nas salas de aula. Além disso, as competições versam sobre os mais variados temas, desde empreendedorismo social, passando por talento musical e cultural até monografias sobre finanças públicas; o que é de grande valia, pois permite a participação de universitários de diversos cursos, não havendo uma restrição contundente de áreas de interesse.

\section{Considerações Finais}

Os concursos acadêmicos foram uma forma encontrada pelas instituições de incentivar o aprendizado e a estimular que os estudantes busquem ultrapassar seus limites cognitivos, em que, por meio da apresentação de um caso concreto para discussão, de uma simulação ou necessidade de encontrar soluções para problemas, os alunos são desafias a apresentar suas capacidades, habilidades e conhecimentos adquiridos no decorrer de sua vida acadêmica.

Nesse cenário, apesar de, por vezes, estarem dessincronizados dos calendários acadêmicos, bem como fora do âmbito de controle e gestão do corpo docente, essas competições acadêmicas apresentam forte viés e características de metodologia ativa de aprendizado, o que é indício de que esse tipo de iniciativa pode ser utilizado de forma eficaz como forma de ensino e aprendizagem, a ser utilizado não apenas pelas instituições, como também pelos professores e alunos. Dessa forma, se apresentam como alternativa interessante de aprendizagem aos estudantes universitários, na forma de atividade complementar à formação acadêmica dos alunos.

Outrossim, outro ponto positivo relacionado aos concursos acadêmicos é que as competições servem de forma de aprendizagem não apenas para os alunos, como também para os professores, sendo esse o diferencial das metodologias ativas de ensino.

Contudo, como não são todos as instituições que se preocupam em elaborar um concurso acadêmico com vistas a oportunizar e estimular a aprendizagem estudantil, isto porque nem toda competição nasce com a ideia de colaborar com o desenvolvimento das habilidade e ampliação dos conhecimentos estudantis. Isso foi confirmado com os dados da pesquisa 
realizada pela McKinsey and Company, que revelou que apenas um terço dessas competições apresentam essas características na atualidade, não sendo possível afirmar que esse tipo de iniciativa deve ser incorporado como atividade obrigatória na formação acadêmica universitária.

Com base no exposto, nota-se que as competições acadêmicas são um método exitoso de incentivo a aprendizagem, configurando algo favorável e complementar à formação estudantil, mas, que, no entanto, ainda não apresenta as características necessárias para ser incorporada como obrigatória na grande curricular, uma vez que nem todas as competições universitárias carregam como objetivo principal o incentivo ao ensino e aprendizagem e a aprimoração das capacidades e habilidades do universitário.

\section{Referências}

ALCADIPANI, R.; BRESLER, R. A macdonaldização do ensino. Carta Capital, 10 de Maio. São Paulo: Ed. 133, 1999.

BALlantyne, P. Challenge Prizes: A Practice Guide. England: NESTA - Center for Challenge Prizes, 2014.

BASTOS, Y. B.; KUULUVAINEN, S.; BRAGA, C. S. Leveraging the learning experiences in sustainability-oriented Challenge Prizes. Sweden: Blekinge Institute of Technology Karlskrona, 2015

BACKES, D. S.; MARINHO, M.; COSTENARO, R. S.; NUNES, S.; RUPOLO, I. Repensando o ser enfermeiro docente na perspectiva do pensamento complexo. Revista Brasileira de Enfermagem. Brasília, v. 63, n. 3, p. 421-426, mai./jun. 2010.

BEST, J. Prize proliferation. Sociological Forum, v.23, n.1, p.1-27, 2008.

BIGGS, J.; TANG, C. Teaching for quality learning at university. Buckingham: Society for research into higher education, 2007.

CHAHUÁN-JIMÉNEZ, K. Evaluación cualitativa y gestión del conocimiento. Educación y Educadores. Chia, v. 12, n. 3, p. 179-195, set./dez. 2009.

ENAGO ACADEMY. Qual a importância das competições acadêmicas? 2015. Disponível em: < http://www.enago.com.br/blog/qual-a-importancia-das-competicoes-academicas/>. Acesso em 20/12/2018.

FREY, B. S.; NECKERMANN, S. Awards: a view from psychological economics. Zeitschrift für Psychologie/Journal of Psychology, v. 216, n. 4, p. 198-208, 2008. 
FREY, B. S.; GALLUS, J. Awards are a special kind of signal. Zurich: Center for Research in Economics, Management and the Arts (CREMA), 2014.

HADDAD, M. C. L.; VANNUCHI, M. T. O.; TAKAHASHI, O. C.; HIRAZAWA, S. A.; RODRIGUES, I. G.; CORDEIRO, B. R.; CARMO, H. M. Enfermagem médico-cirúrgica: uma nova abordagem de ensino e sua avaliação pelo aluno. Revista Latino-Americana de Enfermagem. Ribeirão Preto, v. 1, n. 2, p. 97-112, jul. 1993.

HARRISON, B.; JEPSEN, D. M. The career impact of winning an external work-related award. Journal of Vocational Behavior, v. 89, p. 21-31, 2015.

LOURENÇO, Abílio Afonso; DE PAIVA, Maria Olímpia Almeida. A motivação escolar e o processo de aprendizagem. Revista Interdisciplinar de Estudo da Cognição. v. 15, n. 2, 2010.

MASSETO, M. T. Novas tecnologias e mediação pedagógica. São Paulo: Papirus, 2007.

MCKINSEY AND COMPANY. And the winner is...Capturing the promise of philanthropic prizes, 2009. Disponível em: < https://www.mckinsey.com/industries/social-sector/ourinsights/and-the-winner-is-philanthropists-and-governments-make-prizes-count $>$. Acesso em: 20/12/2018.

MEZZARI, A. O uso da Aprendizagem Baseada em Problemas (ABP) como reforço ao ensino presencial utilizando o ambiente de aprendizagem Moodle. Revista Brasileira de Educação Médica. Rio de Janeiro. v. 35, n. 1, p. 114-121, jan./mar. 2011.

NICOLINI, A. Qual será o futuro das fábricas de administradores? RAE, Salvador, v. 43, n. 2, p. 44-54, abr./jun. 2003.

OLIVEIRA, P. M.; MURITIBA, S. N; CASADO, T. Diferenças individuais dos estudantes e preferência por métodos de ensino em Administração: uma aplicação dos tipos psicológicos de Jung, 2005. Brasília - DF: Anais do ENANPAD, 2005.

PATI, Camila. 10 competições universitárias com prêmios de até R\$ 58 mil. Revista Exame.com. Disponível em: <https://exame.abril.com.br/carreira/10-competicoesuniversitarias-com-premios-de-ate-r-58-mil/> . Acesso em: 20/12/2018.

PINHO, S. T.; ALVES, D. M.; GRECO, P. J.; SCHILD, J. F. G. Método situacional e sua influência no conhecimento tático processual de escolares. Motriz: Revista de Educação Física. Rio Claro, v. 16, n. 3, p. 580-590, jul./set. 2010

RANGEL, Mary. Métodos de ensino e aprendizagem e dinamização das aulas. Campinas: Papirus Editora, 3ed, 2005.

SPINK, P. A inovação na perspectiva dos inovadores. In: IX Congresso Internacional Del Clad Sobre La Reforma Del Estado Y De La Administración Pública, 2004, Madrid.

TEÓFILO, T. J. S.; DIAS, M. S. A. Concepções de docentes e discentes acerca de metodologias de ensino-aprendizagem: análise do caso do Curso de Enfermagem da Universidade Estadual 
Vale do Acaraú em Sobral - Ceará. Interface - Comunicação, Saúde, Educação. Botucatu, v. 13, n. 30, p. 137-151, jul./set. 2009.

WEINTRAUB, M.; HAWLITSCHEK, P.; JOÃO, S. M. A. Jogo educacional sobre avaliação em fisioterapia: uma nova abordagem acadêmica. Fisioterapia e Pesquisa. São Paulo, v. 18, n. 3, p. 280-286, jul./set. 2011.

\section{Como citar este artigo (Formato ABNT):}

FERNANDES, Rivalina Maria Macêdo; BEZERRA, Martha Maria Macedo; BARRETO, Julyanne de Oliveira Paes; FARIAS, Athena de Albuquerque. Competições de conhecimentos universitários: Método inovador de incentivo à aprendizagem. Id on Line Rev.Mult. Psic., 2018, vol.12, n.42, Supl. 1, p. 861-875. ISSN: 1981-1179.

Recebido: 14/11/2018;

Aceito: 17/11/2018 